\title{
Translation, Cultural Adaptation and Validation of the Power of Food Scale for Use by Adult Populations in Portugal
}

\author{
Tradução, Adaptação Cultural e Validação da Escala do Poder da Comida para \\ Utilização por Populações de Adultos em Portugal
}

Gabriela RIBEIRO ${ }^{1,2}$, Osvaldo SANTOS ${ }^{3,4}$, Marta CAMACHO ${ }^{1,5}$, Sandra TORRES ${ }^{6}$, Filipa MUCHA-VIEIRA ${ }^{6}$, Daniel

SAMPAIO ${ }^{7,8}$, Albino J. OLIVEIRA-MAIA $\triangle^{1,5,9}$

Acta Med Port 2015 Sep-Oct;28(5):575-582

\section{ABSTRACT}

Introduction: The Power of Food Scale measures appetite for, rather than consumption of, palatable foods - a construct frequently designated as hedonic hunger. The purpose of this study was to examine the psychometric properties of a Portuguese version of the Power of Food Scale, namely reliability and construct validity.

Material and Methods: Data was obtained from 1266 adult participants sampled from three different populations in Portugal: two nonclinical samples and one multi-center sample of severely obese candidates for weight-loss surgery.

Results: We found that the factor structure of the Portuguese version of the Power of Food Scale is similar to that of the original scale and that the Portuguese version of the Power of Food Scale has good internal structure, test-retest reliability and construct validity. In addition, we provide the first contribution towards defining population norms for Power of Food Scale scores.

Discussion: The Portuguese version of the Power of Food Scale proved to have good psychometric properties: it is a valid and reliable tool for measuring hedonic hunger, supporting its use both in clinical and non-clinical samples, as well as in prospective studies.

Conclusion: Our results show that the Portuguese version of the Power of Food Scale is a useful measure for researchers and clinicians who are interested in exploring the construct of hedonic hunger in Portuguese-speaking populations, including those suffering from obesity.

Keywords: Appetitive Behavior; Feeding Behavior; Psychometrics; Questionnaires.

\section{RESUMO}

Introdução: A Power of Food Scale é uma escala que avalia um constructo designado por fome hedónica, frequentemente definido como o apetite por alimentos de elevada palatibilidade, mais do que a sua ingestão propriamente dita. Este estudo teve como objetivo a caracterização das propriedades psicométricas de uma versão portuguesa da Power of Food Scale, nomeadamente da sua fiabilidade e validade de constructo.

Material e Métodos: Os dados foram obtidos de 1266 participantes adultos, provenientes de três amostras distintas: duas amostras não clínicas e uma amostra clínica de indivíduos com obesidade severa, candidatos a cirurgia da obesidade.

Resultados: Verificamos que a estrutura factorial da versão portuguesa da Power of Food Scale é semelhante à do questionário original e que apresenta fiabilidade teste-reteste e validade de constructo adequadas. Adicionalmente, apresentamos neste estudo o primeiro contributo para a definição de normas populacionais para os scores da Power of Food Scale.

Discussão: A versão portuguesa da Power of Food Scale apresentou boas propriedades psicométricas: é um instrumento válido e fiável para a avaliação do constructo fome hedónica, suportando a sua utilização tanto em amostras clínicas como não clínicas, bem como em estudos longitudinais.

Conclusão: Estes resultados demostram que a versão portuguesa da Power of Food Scale é um instrumento útil, tanto em contexto clínico, como de investigação, nomeadamente para o estudo do constructo fome hedónica em populações de língua portuguesa, incluindo populações clínicas de indivíduos com obesidade.

Palavras-chave: Comportamento Alimentar; Comportamento Apetitivo; Psicometria; Questionários.

\section{INTRODUCTION}

Over the past decades, obesity has become a global health problem. Worldwide, an estimated 1.5 billion adults are overweight (body mass index (BMI) between 25.0 and $\left.29.9 \mathrm{Kg} / \mathrm{m}^{2}\right)$ or obese $\left(\mathrm{BMI} \geq 30 \mathrm{Kg} / \mathrm{m}^{2}\right)$. Once a problem exclusive to developed nations, obesity now impacts countries across the development spectrum. ${ }^{1}$ Portugal,

where this study was conducted, is no exception, with $39.4 \%$ of the population being overweight, and $14.2 \%$ obese. $^{2}$ It is widely acknowledged that obesity is determined by complex interactions between environmental and genetic factors, mediated by equally complex neuronal and hormonal systems. ${ }^{3}$ Among the environmental factors thought to

\footnotetext{
1. Neuropsychiatry Unit. Champalimaud Clinical Centre. Champalimaud Centre for the Unknown. Lisboa. Portugal.

2. Metabolic Diseases and Eating Behaviour Programme. Faculdade de Medicina. Universidade de Lisboa. Lisboa. Portugal.

3. Institute of Preventive Medicine and Public Health. Faculdade de Medicina. Universidade de Lisboa. Lisboa. Portugal.

4. DECO PROTESTE. Lisboa. Portugal.

5. Champalimaud Neuroscience Programme. Champalimaud Centre for the Unknown. Lisboa. Portugal.

6. Faculdade de Psicologia e de Ciências da Educação. Universidade do Porto. Porto. Portugal.

7. Department of Psychiatry. Centro Hospitalar de Lisboa Norte. Lisboa. Portugal.

8. Department of Psychiatry. Faculdade de Medicina. Universidade de Lisboa. Lisboa. Portugal.

9. Department of Psychiatry and Mental Health. Centro Hospitalar de Lisboa Ocidental. Lisboa. Portugal.

$\square$ Autor correspondente: Albino J. Oliveira-Maia. albino.maia@neuro.fchampalimaud.org

Recebido: 15 de Abril de 2015 - Aceite: 09 de Junho de 2015 | Copyright @ Ordem dos Médicos 2015
} 
underlie increasing levels of obesity are dramatic changes in food environment, affecting food intake and increasing the energy density of diets. ${ }^{4}$

Overeating plays a fundamental role in obesity and can result, at least in part, from the experience of pleasure that is associated with the consumption of highly palatable foods. ${ }^{5}$ In fact, certain foods, particularly those rich in sugar and fat, activate dopaminergic reward circuits in the central nervous system through both oral and post-oral mechanisms, ${ }^{6,7}$ leading to increased consumption of those foods. ${ }^{8}$ There is significant inter-individual variability in sensitivity to the reward value of food and reactivity to food cues, ${ }^{9,10}$ in part reflecting the presence of genetic determinants that may predispose individuals to overeating and obesity. ${ }^{11}$ Additionally, the consumption of palatable foods has been shown, in itself, to modify dopaminergic circuits and induce compulsive food consumption in rodents, ${ }^{12}$ which could explain the presence of similar changes of striatal dopamine $D_{2}$ receptors in morbidly obese patients. ${ }^{13}$

The Power of Food Scale (PFS) is a self-report measure designed to assess individual sensitivity to palatable foods in food-abundant environments. ${ }^{14}$ It has been proposed to measure a construct designated as hedonic hunger, i.e., the drive to consume food in order to obtain pleasure, occurring even in the absence of an energetic requirement. ${ }^{15}$ The scale includes items that assess frequency of thoughts about food in the absence of physical hunger, level of pleasure associated with eating, and urges to eat when exposed to food stimuli, independently of food consumption itself. PFS items were designed to measure the hedonic impact of food abundant environments involving three levels of food proximity: (1) food available in the environment but not physically present, (2) food present but not tasted and (3) food when first tasted but not yet consumed. ${ }^{14}$ The original PFS, developed for the adult population in the USA, has high reliability ${ }^{16}$ and adequate 4-month test-retest reliability. ${ }^{14}$ Elevated PFS scores have been associated to both obesity ${ }^{17,18}$ and binge eating. ${ }^{19,20}$ Furthermore, fasting periods equivalent to regular breaks between meals (e.g., 4 hours) are not associated with changes in scores on the PFS, suggesting that hedonic hunger is a stable construct that is not considerably affected by daily variations in physical or homeostatic hunger. ${ }^{21}$

This study had two main purposes. The first was to develop a Portuguese version of the PFS (P-PFS) and to examine its psychometric properties. This included the evaluation of its reliability (internal consistency and temporal stability) and its construct validity (factor structure, convergent, divergent and discriminative validities). Additionally, we established population norms for P-PFS scores in the Portuguese adult population.

\section{MATERIAL AND METHODS}

This study followed an observational design with both cross-sectional and longitudinal components. Data were collected using self-administered questionnaires filled-in using a paper and pencil format. The study protocol was approved by the Ethics Committees at the Champalimaud Foundation (Lisbon), University of Lisbon School of Medicine, University of Évora and Hospital S. João (Porto). Written informed consent was obtained from all participants.

\section{Participants and Procedure}

Data were collected from November 2012 to February 2014 in three groups of participants: a sample of college and vocational school students (non-clinical sample), a general Portuguese adult population sample (population sample), and a sample of obese patients candidates for weight-loss surgery (clinical sample). The non-clinical sample was recruited from three education institutions using non-probabilistic sampling. The population sample was obtained through a randomized population mailbased survey organized by the main Portuguese consumer association (DECO PROTESTE). A mail-out and mailback method was used, with 10000 questionnaires sent out to a representative adult (18 to 74 year-old) sample, proportionally stratified by gender, age and geographical regions, according to the 2011 Portuguese Census. ${ }^{22}$ Postal address files were purchased from a commercially available mailing list and a questionnaire, introduction letter and a pre-paid return envelope were sent to each of the potential respondents. No reminder letter was sent and all responses were fully anonymous.

The clinical sample was recruited using sequential sampling at the weight-loss surgery clinic of Hospital do Espírito Santo, in Évora, and Hospital S. João, in Porto. Patients were excluded if presenting psychiatric, neurological or gastrointestinal disease or if substance or alcohol abuse were reported.

\section{Material}

Power of Food Scale (PFS): The creation of the P-PFS followed a formal translation and back-translation method. The original English-language version of the PFS was independently translated into Portuguese by three bilingual (first language Portuguese) research-team members, with expertise in Psychiatry, Clinical Psychology and Clinical Nutrition. A consensus version of the two translations was obtained through discussion with additional research-team members with similar expertise. The consensus version was independently backward-translated into English by two bilingual dietitians (first language English) that are not a part of the research team. The research team and the senior author of the original English version resolved discrepancies between the original version and the backward-translation, leading to minor adjustments in the Portuguese consensus translation. Additional minor adjustments were also performed after cognitive interview with 17 obese and normal weight individuals that completed a preliminary version of the P-PFS. A final P-PFS was thus obtained, with similar lay-out, the same likert-type scale of answer and the same number of items as the original PFS, and was used for all participants in the study. Test-retest reliability was determined in a subgroup of the non-clinical 
sample (college students) by repeated administration of the P-PFS after a four-week interval.

Dutch Eating Behavior Questionnaire (DEBQ): The $D E B Q^{23}$ is a self-report questionnaire consisting of 33 items following a likert-type scale of answer, ranging from 'never' to 'very often'. It comprises three dimensions, measuring restraint (attempts to avoid food ingestion), emotional eating (overeating in response to emotions) and external eating (eating in response to food-related stimuli). The DEBQ has been validated for the Portuguese population by Viana et $\mathrm{al}^{24}$ and was used here to assess construct validity of the P-PFS (convergent and divergent validity) in a subgroup of the non-clinical sample (vocational school students) and in the clinical sample.

Binge Eating Scale (BES): The BES ${ }^{25}$ is a 16 -item selfreport questionnaire designed to assess both binge-related behavioral manifestations (e.g., eating large amounts of food) and feelings/cognitions relating to a binge episode (e.g., guilt, fear of being unable to stop eating). The Portuguese version of the BES was validated by Tapadinhas et al (Tapadinhas et al, personal communication, 2015). It was also used to assess convergent validity of P-PFS in a subgroup of the non-clinical sample (vocational school students).

Eating Disorder Inventory (EDI): The EDI ${ }^{26}$ is a selfreport questionnaire designed to measure psychological and behavioral traits, commonly found in eating disorders. This 64-item questionnaire consists of eight subscales: Drive for thinness, bulimia, body dissatisfaction, ineffectiveness, perfectionism, interpersonal distrust, interoceptive awareness, and maturity fears. Responses to items are given through a 6-point likert-type scale, ranging from 'always' to 'never'. The Portuguese version of the EDI was validated by Machado et $\mathrm{al}^{27}$ and was used to assess construct validity of the P-PFS (convergent and divergent validity) in a subgroup of the non-clinical sample (vocational school students).

Newest Vital Sign (NVS): The NVS ${ }^{28}$ is a health literacy assessment instrument that consists of an ice cream nutrition label and six related questions. Two of the questions involve locating information and four involve numerical calculations. Each correct answer receives one point, and participants are given a score of 0 to 6 , which is based on how many questions they answer correctly. This instrument is being validated for the Portuguese population by Santos et $\mathrm{al}^{29}$ and was used to assess divergent validity of PFS in a subgroup of the non-clinical sample (vocational school students) and in the clinical sample.

\section{Data Analysis}

Statistical analysis was conducted with SPSS 22.0 for Windows and with AMOS v22 for confirmatory analysis of the P-PFS structure. All continuous measurements were normally distributed, as per analysis of kurtosis, skewness and comparison of mean and median. Results are presented as mean $(\mathrm{M}) \pm$ standard deviation $(\mathrm{SD})$ or standard error of the mean (SEM).

The collected population sample deviated slightly from the 2011 Portuguese Census, ${ }^{22}$ regarding gender, age, education and regional distributions. These deviations were corrected by weighting the data, in order to maintain sampling proportionality. ${ }^{30}$

Table 1 - Demographic information of the non-clinical and the clinical samples

\begin{tabular}{|c|c|c|c|}
\hline & & $\begin{array}{l}\text { Non-clinical Sample } \\
\qquad(n=278)\end{array}$ & $\begin{array}{c}\text { Clinical Sample } \\
\qquad(n=123)\end{array}$ \\
\hline \multirow{2}{*}{ Gender } & Women & $66.5 \%$ & $87.8 \%$ \\
\hline & Men & $33.5 \%$ & $12.2 \%$ \\
\hline \multirow{7}{*}{ Age } & $18-24$ years old & $72.3 \%$ & $2.4 \%$ \\
\hline & $25-34$ years old & $18.7 \%$ & $21.1 \%$ \\
\hline & $35-44$ years old & $9.0 \%$ & $30.9 \%$ \\
\hline & $45-54$ years old & $0.0 \%$ & $27.7 \%$ \\
\hline & $\geq 55$ years old & $0.0 \%$ & $17.9 \%$ \\
\hline & Mean (years) & 23.1 & 43.6 \\
\hline & Standard Deviation & 6.4 & 10.6 \\
\hline \multirow{5}{*}{$\begin{array}{l}\text { Education } \\
\text { (years of formal education) }\end{array}$} & Low (9 years or less) & $19.4 \%$ & $55.3 \%$ \\
\hline & Medium (10 to 12 years) & $33.5 \%$ & $26.8 \%$ \\
\hline & High (13 years or more) & $47.1 \%$ & $17.9 \%$ \\
\hline & Mean (years) & 11.3 & 9.7 \\
\hline & Standard Deviation & 2.1 & 4.6 \\
\hline
\end{tabular}


Factorial structure of the P-PFS was examined with principal components analysis performed with the 15 items of this instrument, using data from the non-clinical sample. An item was considered to load on a factor when the absolute factor loading was greater than for any other factor and also greater than 0.4 . Confirmatory factor analysis was performed using structural equation modeling, with data from the population sample. The construct model was evaluated using several fit indices (see results for details), including the normed chi-square index, calculated according to the maximum likelihood estimation chi-square, divided by the degrees of freedom.

Reliability was assessed using the alpha coefficient. Test-retest reliability was estimated using the standard error of measurement and respective two-way mixed intra-class correlation coefficient single-measure (ICC). Pearson's correlation was used to assess construct validity. Comparison of means were performed with independent samples t-test or one way ANOVA followed by post-hoc Tukey test for comparison between homogeneous subsets.

\section{RESULTS}

\section{Sample characteristics}

A summary of demographic characteristics for participants in this study is given in Table 1 and Fig. 1. Overall, the non-clinical sample (Table 1) included 278 participants. Of 129 college students and 149 vocational school students recruited, 104 and 143 respectively completed the study protocol. Ages ranged from 18 to 50 years and women comprised $66.5 \%$ of the sample. BMI for most participants in this sample (82.4\%) was below $25 \mathrm{~kg} / \mathrm{m}^{2}$. Regarding the population sample (Fig. 1), 865 participants returned fully filled out questionnaires. In this sample, $56 \%$ of participants were women and ages ranged from 18 to 74 years of age $(M=48.3$; $S D=14.9$ years $)$. Regarding the clinical sample (Table 1), from 159 patients, 123 were eligible and accepted to participate. Here, the gender distribution was even more skewed towards a predominance of women than the other two groups (87.8\% women). As expected, $\mathrm{BMI}$ was higher than in the remaining participants, ranging from 34.5 to $61.5 \mathrm{Kg} / \mathrm{m}^{2}$. Furthermore, contrary to the nonclinical and the population samples, most of the participants $(55.3 \%)$ had low educational level (i.e., 9 or fewer years of formal education). Across the several samples, significant differences were not found for P-PFS scores according to gender, geographical region or education (data not shown). Significant negative correlation was found between P-PFS aggregate score and age for the population sample $(r=$ -0.149; $p<0.001$ ) but not for the clinical and non-clinical samples.

\section{Reliability}

For the non-clinical sample, P-PFS item-total correlations ranged from 0.4 to 0.68 and the alpha coefficient was 0.88 . For the population sample, the alpha coefficient was 0.91 and item-total correlations ranged from 0.42 to 0.71 . Four-

\begin{tabular}{|c|c|c|c|c|c|c|c|}
\hline & & \multicolumn{2}{|c|}{$\begin{array}{l}\text { Women } \\
n=484\end{array}$} & \multicolumn{2}{|c|}{$\begin{array}{c}\text { Men } \\
n=361\end{array}$} & \multicolumn{2}{|c|}{$\begin{array}{c}\text { Total } \\
n=865\end{array}$} \\
\hline & & $n$ & $\%$ & $n$ & $\%$ & $\mathrm{n}$ & $\%$ \\
\hline \multirow{8}{*}{ Age } & $18-24$ years old & 18 & 3.7 & 10 & 2.6 & 28 & 3.2 \\
\hline & 25 - 34 years old & 122 & 25.2 & 50 & 13.1 & 172 & 19.9 \\
\hline & $35-44$ years old & 132 & 27.3 & 59 & 15.5 & 191 & 22.1 \\
\hline & 45 - 54 years old & 80 & 16.5 & 57 & 15.0 & 137 & 15.8 \\
\hline & $55-64$ years old & 88 & 18.2 & 94 & 24.7 & 182 & 21.0 \\
\hline & $65-74$ years old & 44 & 9.1 & 111 & 29.1 & 155 & 17.9 \\
\hline & Mean (years) & \multicolumn{2}{|c|}{44.4} & \multicolumn{2}{|c|}{53.1} & \multicolumn{2}{|c|}{48.3} \\
\hline & SD & \multicolumn{2}{|c|}{13.5} & \multicolumn{2}{|c|}{15.2} & \multicolumn{2}{|c|}{14.9} \\
\hline \multirow{5}{*}{$\begin{array}{l}\text { Education } \\
\text { level }^{+}\end{array}$} & Low & 86 & 18.1 & 115 & 30.6 & 201 & 23.6 \\
\hline & Medium & 142 & 29.9 & 120 & 31.9 & 262 & 30.8 \\
\hline & High & 247 & 52.0 & 141 & 37.5 & 388 & 45.6 \\
\hline & Mean (years) & \multicolumn{2}{|c|}{13.3} & \multicolumn{2}{|c|}{12.0} & \multicolumn{2}{|c|}{12.7} \\
\hline & SD & \multicolumn{2}{|c|}{4.2} & \multicolumn{2}{|c|}{4.3} & \multicolumn{2}{|c|}{4.3} \\
\hline
\end{tabular}

+ "Low level": 9 or less years of school; "Medium level": 10 to 12 years of school; "High level": More than 12 years of formal education.

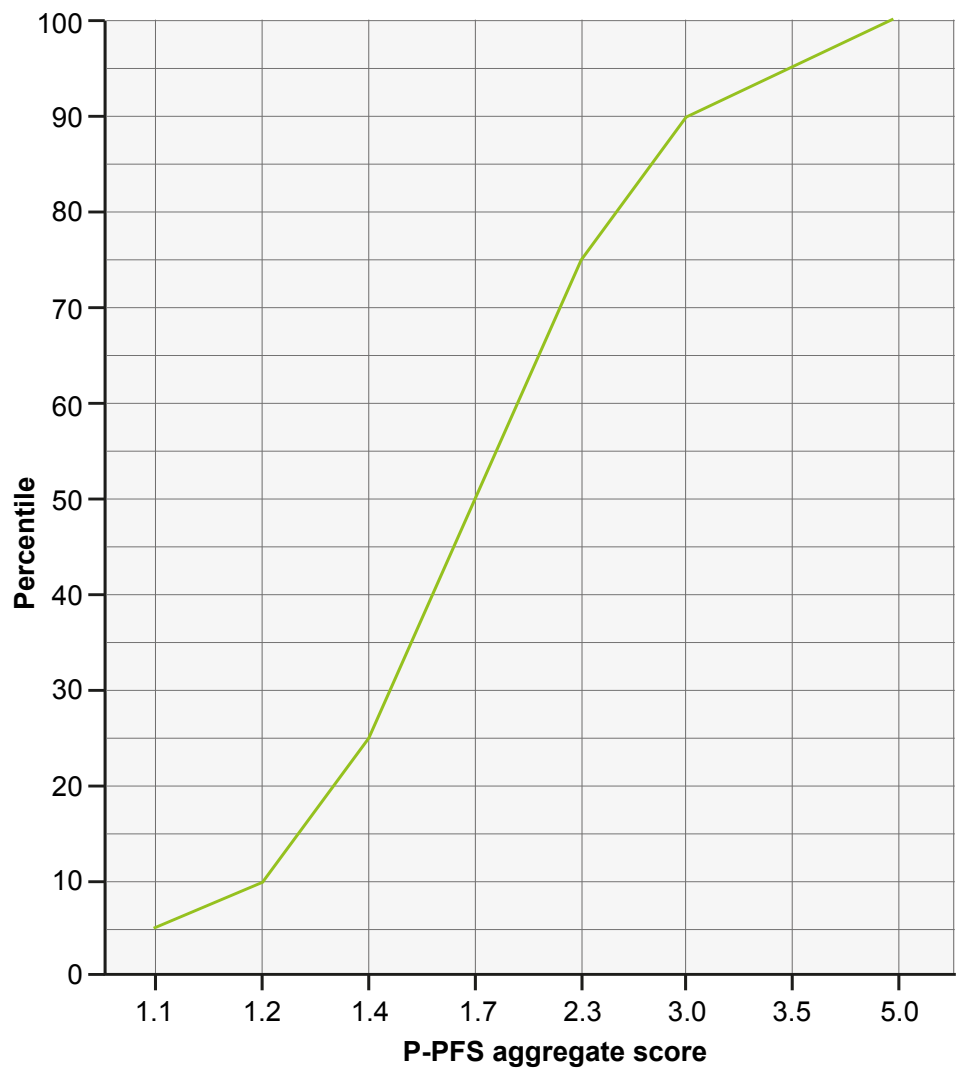

Figure 1 - P-PFS aggregate scores in the population sample. Here we show information regarding age, gender and education in participants of the population sample $(n=865)$, and mean P-PFS aggregate scores for the several resulting age/gender and education/ gender subgroups. In the right panel the percentile curve of the P-PFS aggregate score is shown. 
week test-retest reliability, tested in a subgroup of the nonclinical sample (college students), was adequate $(\mathrm{ICC}=$ 0.84).

\section{Factor analysis}

The factorial structure of the P-PFS was tested with data from the non-clinical sample. The Kaiser-Meyer-Olkin measure of sampling adequacy was 0.902 , indicating a high adequacy for the factor analysis. The Bartlett's test of sphericity yielded a high chi-square value $\left(\chi^{2}=1436\right.$; $p<0.001$ ), indicating that a factor model is appropriate. Principal Component Analysis with varimax rotation revealed a model with three factors, explaining $54.2 \%$ of the total variance. Fig. 2 shows the scree plot curve for this analysis, inflecting at the third factor. When comparing the factors found here with those proposed for the original PFS, we observed that our first factor, explaining $38.60 \%$ of total variance, included the same six items from the original PFS 'food available' dimension, and two additional items that, in the original PFS, belong to other dimensions: item 7, 'I love the taste of certain foods so much that I can't avoid eating them even if they're bad for me' (from the 'food present' dimension, in the original PFS) and item 12, 'Hearing someone describe a great meal makes me really want to have something to eat' (from the 'food tasted' dimension, in the original PFS). Our second factor explaining $8.4 \%$ of total variance, included four of the five 'food tasted' items, while our third factor, explaining $7.19 \%$ of variance, included three of the four 'food present' items. Taking into account the nature of the items that resulted from the factor analysis of the P-PFS data, we decided to keep the same labelling of the original PFS factors: 'food available' (factor one, now aggregating eight, rather than six items), 'food tasted' and 'food present' (factors two and three respectively, each with one item less than the original PFS).

This three-factor model was tested using confirmatory factor analysis with data from the population sample, and was found to be acceptable. The root mean square error of approximation (0.046) was smaller than the maximum fit value of .05 and the adjusted goodness of fit index (0.91) was above the minimum of 0.9 . The normed chisquare index (3.3) was slightly above the maximum of 3. Incremental fit indices were all above the accepted minimum of 0.9 (normed fit index $=0.93$, comparative fit index $=0.95$ and Tucker-Lewis index coefficient $=0.93$ ) . Finally, parsimonious fit of the model (parsimonious normed fit index $=0.77$ ) was smaller than incremental fit values, though still acceptable.

\section{Construct validity}

Measures of construct validity were assessed in a subgroup of the non-clinical sample (vocational school students) and in the clinical sample. In the non-clinical sample, the P-PFS aggregate score was weakly correlated with only five out of the eight dimensions of the EDI (interoceptive awareness, bulimia, body dissatisfaction, maturity fears, drive for thinness) and with the overall score of the BES. Similar correlations were found for the P-PFS subdomains scores (Table 2). Both in clinical and nonclinical sample, strong correlations were found between the P-PFS aggregate score and the DEBQ external eating subscale, as well as the DEBQ emotional eating subscale. Similar correlations were found between the P-PFS 'food available' subdomain score and these DEBQ subscales, but correlations with the 'food tasted' and 'food present' subdomain scores were not as strong. Regarding the DEBQ

\begin{tabular}{lccc}
\hline & $\begin{array}{c}\text { Factor 1 } \\
\text { Food available } \\
\mathbf{3 8 . 6 0 \%}\end{array}$ & $\begin{array}{c}\text { Factor 2 } \\
\text { Food tasted } \\
\mathbf{8 . 4 0 \%}\end{array}$ & $\begin{array}{c}\text { Factor 3 } \\
\text { Food present } \\
\mathbf{7 . 1 9} \%\end{array}$ \\
\hline PFS 1 & 0.563 & & \\
PFS 2 & 0.648 & & 0.685 \\
PFS 3 & & & 0.798 \\
PFS 4 & & & \\
PFS 5 & 0.657 & & 0.720 \\
PFS 6 & & & \\
PFS 7 & 0.410 & 0.708 & \\
PFS 8 & & 0.815 & \\
PFS 9 & & & \\
PFS 10 & 0.593 & & \\
PFS 11 & 0.721 & 0.75 \\
PFS 12 & 0.461 & 0.404 & \\
PFS 13 & 0.801 & & \\
PFS 14 & & 0.535 & \\
PFS 15 & & & \\
Alpha \\
coefficient & $\mathbf{0 . 8 3}$ & & \\
\hline & & & \\
\hline
\end{tabular}

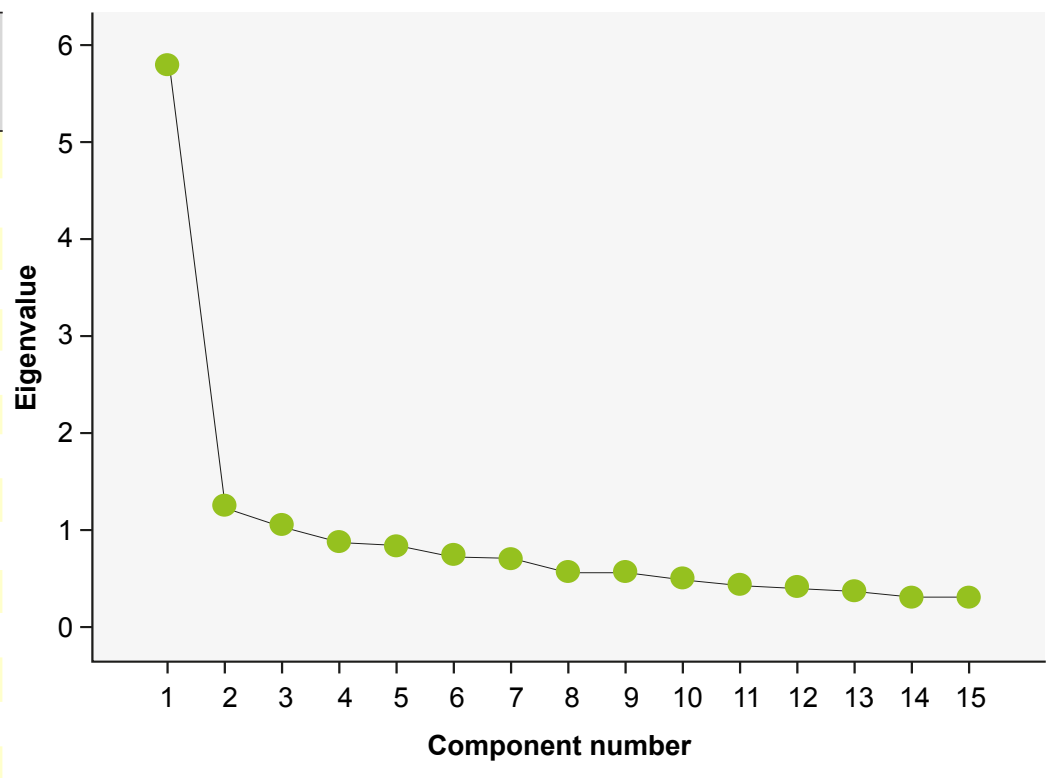

Figure 2 - P-PFS factorial analysis. Varimax rotated 3-factor solution of the P-PFS (15 items) and respective scree plot of eigenvalues (non-clinical sample, $\mathrm{n}=278$ ). 
restraint subscale, it was found to be weakly correlated only with the 'food available' P-PFS score in the non-clinical sample, and weakly inversely correlated with the P-PFS aggregate score and several subdomain scores in the clinical sample. No correlations were found between the NVS and P-PFS scores neither in the clinical nor in the nonclinical sample (Table 2).

\section{Population norms}

In the adult Portuguese population sample, the average P-PFS aggregate score was $\mathrm{M}=1.94$ (median $=1.73 ; \mathrm{SD}=$ 0.72 ); for the food available subdomain, $M=1.61$ (median = 1.33; $S D=0.72$ ); for the food present dimension, the mean was $\mathrm{M}=2.22$ (median $=2.0 ; \mathrm{SD}=0.98$ ) and, finally, for the food tasted factor, the mean was $\mathrm{M}=2.13$ (median = 2.0; $S D=0.81$ ) (Fig. 1). The percentile curve for P-PFS aggregate scores is presented in Fig. 1, according to data collected in the population sample.

\section{DISCUSSION}

In this study we formally translated and validated the PFS for a Portuguese-speaking adult population. The P-PFS proved to have good psychometric properties: it is a valid and reliable self-assessment tool for measuring hedonic hunger in Portuguese-speaking populations. The scale has high internal consistency, ranging from 0.88 (nonclinical sample) to 0.91 (population sample), clearly above the minimum recommended for research tools $(0.8),{ }^{31}$ and similar to what was found for the original PFS ( 0.81 to 0.91$).{ }^{16}$ Temporal stability was also adequate, as found previously for the original version, ${ }^{14}$ supporting use of the P-PFS in prospective studies. In further accordance with prior studies, ${ }^{14,16}$ no gender dependent differences were found in aggregate PFS scores and we also did not find differences according to age or education. Exploratory factor analysis in data from mostly normal weight university and vocational school students supported a three-factor solution: 'food available', 'food present', and 'food tasted'. This is consistent

Table 2 - Correlations between the P-PFS, EDI, BES, DEBQ and NVS

\begin{tabular}{|c|c|c|c|c|c|c|c|c|c|c|}
\hline & \multicolumn{10}{|c|}{ P-PFS } \\
\hline & \multicolumn{5}{|c|}{ Non-clinical sample } & \multicolumn{5}{|c|}{ Clinical sample } \\
\hline & $\begin{array}{l}\text { Aggregate } \\
\text { score }\end{array}$ & $\begin{array}{c}\text { Food } \\
\text { Available }\end{array}$ & $\begin{array}{l}\text { Food } \\
\text { Present }\end{array}$ & $\begin{array}{l}\text { Food } \\
\text { Tasted }\end{array}$ & & $\begin{array}{l}\text { Aggregate } \\
\text { score }\end{array}$ & $\begin{array}{c}\text { Food } \\
\text { Available }\end{array}$ & $\begin{array}{l}\text { Food } \\
\text { Present }\end{array}$ & $\begin{array}{l}\text { Food } \\
\text { Tasted }\end{array}$ & \\
\hline & & $r$ & & & $\mathrm{n}$ & & $r$ & & & $\mathrm{n}$ \\
\hline $\begin{array}{l}\text { EDI - Interoceptive } \\
\text { Awareness }\end{array}$ & $0.26^{* *}$ & $0.31^{* *}$ & 0.14 & $0.17^{*}$ & 143 & & & $\dagger$ & & \\
\hline EDI - Bulimia & $0.19^{*}$ & $0.22^{* *}$ & 0.07 & 0.14 & 143 & & & $\dagger$ & & \\
\hline $\begin{array}{l}\text { EDI - Body } \\
\text { Dissatisfaction }\end{array}$ & $0.18^{*}$ & $0.26^{* *}$ & 0.08 & 0.04 & 143 & & & $\dagger$ & & \\
\hline EDI - Maturity Fears & $0.19^{*}$ & 0.11 & $0.21^{*}$ & 0.13 & 143 & & & $\dagger$ & & \\
\hline $\begin{array}{l}\text { EDI - Drive for } \\
\text { Thinness }\end{array}$ & $0.17^{*}$ & $0.22^{* *}$ & 0.03 & 0.12 & 143 & & & $\dagger$ & & \\
\hline EDI - Ineffectiveness & 0.13 & 0.16 & 0.05 & 0.08 & 143 & & & $\dagger$ & & \\
\hline $\begin{array}{l}\text { EDI - Interpersonal } \\
\text { Distrust }\end{array}$ & 0.04 & 0.07 & -0.01 & 0.00 & 143 & & & $\dagger$ & & \\
\hline EDI- Perfectionism & 0.16 & 0.15 & 0.16 & 0.11 & 143 & & & $\dagger$ & & \\
\hline BES & $0.36^{* *}$ & $0.41^{* *}$ & $0.18^{*}$ & $0.25^{* *}$ & 143 & & & $\dagger$ & & \\
\hline $\begin{array}{l}\text { DEBQ-External } \\
\text { Eating }\end{array}$ & $0.7^{* *}$ & $0.69^{* *}$ & $0.58^{* *}$ & $0.51^{* *}$ & 143 & $0.77^{* *}$ & $0.78^{* *}$ & $0.65^{\star *}$ & $0.61^{* *}$ & 122 \\
\hline $\begin{array}{l}\text { DEBQ-Emotional } \\
\text { Eating }\end{array}$ & $0.4^{* *}$ & $0.46^{* *}$ & $0.27^{* *}$ & $0.23^{* *}$ & 143 & $0.71^{* *}$ & $0.75^{\star *}$ & $0.54^{* *}$ & $0.55^{\text {** }}$ & 122 \\
\hline $\begin{array}{l}\text { DEBQ-Restrained } \\
\text { Eating }\end{array}$ & 0.1 & $0.17^{*}$ & -0.03 & 0.02 & 143 & $-0.22^{*}$ & $-0.24^{* *}$ & -0.11 & $-0.22^{*}$ & 122 \\
\hline Newest Vital Sign & -0.09 & -0.11 & -0.02 & -0.08 & 143 & -0.04 & -0.003 & -0.02 & -0.14 & 114 \\
\hline
\end{tabular}

† This variable was not assessed, for this sample. ${ }^{*} p<0.05 ;{ }^{* *} p<0.01$. P-PFS: Portuguese version of the Power of Food Scale; EDI: Eating Disorder Inventory; BES: Binge Eating Scale; DEBQ: Dutch Eating Behavior Questionnaire; NVS: Newest vital sign. 
with findings reported previously with similar college student samples, ${ }^{14,32}$ and also with overweight adults, ${ }^{16}$ with only minor modifications regarding the items included in each factor, when comparing to the original version of the scale. ${ }^{14}$ Additionally, the confirmatory factor analysis supported this three-factor model of the P-PFS in the populationsample. The P-PFS was found to have convergent validity with measures of external eating, emotional eating and binge eating, and less so with measures of bulimia and interoceptive awareness. Correlations with health literacy were not significant, indicating divergent validity relative to this construct.

In accordance with the results described by Lowe et al, ${ }^{14}$ we found moderate to high correlations between scores for P-PFS and the external eating subscale of the DEBQ, suggesting that these two indicators measure similar aspects of appetite and eating behavior. Since the DEBQ external eating subscale includes items that refer to eating behaviors that are mainly triggered by food stimuli or by the presence of other people eating, it can be hypothesized that this indicator is mainly a measure of the perceived influence of the presence of food, rather than a measure of overeating or binge eating. In fact, correlations between P-PFS and the DEBQ external eating subscale were higher than correlations with the emotional eating subscale or the BES. These findings support the validity of the P-PFS, given that the construct measured by the DEBQ external eating subscale is more similar to that of hedonic hunger than those measured by other DEBQ subscales.

Nevertheless, our results also indicate that external eating and hedonic hunger, while related, are not identical. One unresolved issue is that of a potential differential role of these instruments in the prediction of weight gain. In a Dutch study, conducted prospectively in a representative sample of the general population over a 2-year period, external eating, as assessed by the external eating subscale of the DEBQ, was not associated with BMI change. This finding is in line with results of other prospective studies, ${ }^{33,34}$ suggesting that external eating may not be a good predictor of BMI change. However, in morbidly obese patients from a bariatric surgery clinic, DEBQ external eating subscale scores were significantly reduced after weight-loss surgery, ${ }^{35}$ and similar findings have been reported regarding reduction of PFS scores after weight-loss surgery. ${ }^{17,36}$ Longitudinal studies are thus needed to clarify if PFS and DEBQ subscales, namely the external eating subscale, can serve as predictors of weight gain, presumably acting as markers of hedonically mediated overeating.

This study also provides, for the first time, a contribution to define population-based norms for PFS scores. This was possible due to data collection from a proportional sample of Portuguese adults (18 to 74 years old). Although the interpretation of these results is limited by a low response rate to this population-based survey, it is an asset for the interpretation of individual or summary PFS scores, since they can be compared with population distribution according to the respective percentile. Accordingly, we can observe that, as described above, the mean P-PFS score for the clinical sample $(M=2.52)$ is very close to the $80^{\text {th }}$ percentile of the population distribution, and thus higher than the mean P-PFS score for the non-clinical sample $(\mathrm{M}=2.26)$, which is between the $60^{\text {th }}$ and $65^{\text {th }}$ percentile.

\section{CONCLUSION}

In conclusion, the good psychometric properties (namely, validity and reliability) of the PFS, already established in previous studies, were reproduced in different Portuguesespeaking adult samples, suggesting that the P-PFS is an effective tool for measuring hedonic hunger both in clinical and non-clinical populations. Nevertheless, prospective longitudinal studies using larger clinical samples will be necessary to assess the utility of the PFS in the identification of individuals that may be vulnerable to highly palatable food in terms of several health outcomes, including obesity.

\section{ACKNOWLEDGEMENTS}

The authors would like to thank Michael Lowe from the Department of Psychology, Drexel University, Philadelphia, for providing access to the Power of Food Scale and contributing to the adaptation process. We would also like to thank Faculdade de Ciências da Nutrição e Alimentação da Universidade do Porto, Universidade Atlântica, Instituto do Emprego e Formação Profissional, Universidade de Évora, Hospital Espírito Santo de Évora, and Hospital S. João (in particular Armando Raimundo, Manuel Carvalho, Margarida Pegacho, André Ferreira, and Mónica Silva) for assistance with recruitment of participants.

\section{PROTECTION OF HUMANS AND ANIMALS}

The study protocol was approved by the Ethics Committees at the Champalimaud Foundation (Lisbon), University of Lisbon School of Medicine, University of Évora and Hospital S. João (Porto). Written informed consent was obtained from all participants.

\section{DATA CONFIDENTIALITY}

The authors declare having followed the protocols in use at their working center regarding patient's data publication.

\section{CONFLICTS OF INTEREST}

The authors declare that there are no conflicts of interest.

\section{FINANCING FUNDS}

This work was supported by Fundação para a Ciência e Tecnologia through a Junior Research and Career Development Award from the Harvard Medical SchoolPortugal Program to AJO-M (HMSP/ICJ/0020/2011). EUROCONSUMERS supported costs related to recruitment of the population sample.

\section{CONFLICT OF INTEREST}

None stated. 


\section{REFERENCES}

1. Finucane MM, Stevens GA, Cowan MJ, Danaei G, Lin JK, Paciorek CJ, et al. National, regional, and global trends in body-mass index since 1980: systematic analysis of health examination surveys and epidemiological studies with 960 country-years and 9. 1 million participants. Lancet. 2011;377:557-67

2. do Carmo I, Dos Santos O, Camolas J, Vieira J, Carreira M, Medina L et al. Overweight and obesity in Portugal: national prevalence in 2003 2005. Obes Rev. 2008;9:11-9.

3. Karatsoreos IN, Thaler JP, Borgland SL, Champagne FA, Hurd YL, Hill MN. Food for thought: hormonal, experiential, and neural influences on feeding and obesity. J Neurosci. 2013;33:17610-6.

4. Popkin BM. Global nutrition dynamics: the world is shifting rapidly toward a diet linked with noncommunicable diseases. Am J Clin Nutr. 2006;84:289-98.

5. Davis C, Carter JC. Compulsive overeating as an addiction disorder. A review of theory and evidence. Appetite. 2009;53:1-8.

6. Oliveira-Maia AJ, de Araujo IE, Monteiro C, Workman V, Galhardo V, Nicolelis MA. The insular cortex controls food preferences independently of taste receptor signaling. Front Syst Neurosci. 2012;6:5

7. Oliveira-Maia AJ, Roberts CD, Walker QD, Luo B, Kuhn C, Simon SA, et al. Intravascular food reward. PLoS One. 2011;6:27.

8. Volkow ND, Wang GJ, Baler RD. Reward, dopamine and the control of food intake: implications for obesity. Trends Cogn Sci. 2011;15:37-46.

9. Murdaugh DL, Cox JE, Cook III EW, Weller RE. fMRI reactivity to highcalorie food pictures predicts short-and long-term outcome in a weightloss program. Neuroimage. 2012; 59:2709-21.

10. Epstein LH, Leddy JJ. Food reinforcement. Appetite. 2006;46:22-5.

11. Felsted JA, Ren X, Chouinard-Decorte F, Small DM. Genetically determined differences in brain response to a primary food reward. J Neurosci. 2010;30:2428-32.

12. Johnson PM, Kenny PJ. Dopamine D2 receptors in addiction-like reward dysfunction and compulsive eating in obese rats. Nat Neurosci. 2010;13:635-41.

13. Wang GJ, Volkow ND, Logan J, Pappas NR, Wong CT, Zhu W, et al Brain dopamine and obesity. Lancet. 2001;357:354-7.

14. Lowe MR, Butryn ML, Didie ER, Annunziato RA, Thomas JG, Crerand $\mathrm{CE}$, et al. The Power of Food Scale. A new measure of the psychological influence of the food environment. Appetite. 2009;53:114-8.

15. Lowe MR, Butryn ML. Hedonic hunger: a new dimension of appetite? Physiol Behav. 2007;91:432-9.

16. Cappelleri JC, Bushmakin AG, Gerber RA, Leidy NK, Sexton CC Karlsson J, et al. Evaluating the Power of Food Scale in obese subjects and a general sample of individuals: development and measurement properties. Int J Obes. 2009;33:913-22.

17. Schultes B, Ernst B, Wilms B, Thurnheer M, Hallschmid M. Hedonic hunger is increased in severely obese patients and is reduced after gastric bypass surgery. Am J Clin Nutr. 2010;92:277-83.

18. Ullrich J, Ernst B, Wilms B, Thurnheer M, Hallschmid M, Schultes B. The hedonic drive to consume palatable foods appears to be lower in gastric band carriers than in severely obese patients who have not undergone a bariatric surgery. Obes Surg. 2013;23:474-9.

19. Davis C, Curtis C, Levitan RD, Carter JC, Kaplan AS, Kennedy JL.
Evidence that 'food addiction' is a valid phenotype of obesity. Appetite. 2011;57:711-7.

20. Witt $A A$, Lowe MR. Hedonic hunger and binge eating among women with eating disorders. Int J Eat Disord. 2014;47:273-80.

21. Witt AA, Raggio GA, Butryn ML, Lowe MR. Do hunger and exposure to food affect scores on a measure of hedonic hunger? An experimental study. Appetite. 2013;21:1-5.

22. Instituto Nacional de Estatística. Censos 2011. Resultados Definitivos - Portugal. Lisboa: Instituto Nacional de Estatística I.P; 2011. p. 8726493.

23. Van Strien T, Frijters JE, Bergers G, Defares PB. The Dutch Eating Behavior Questionnaire (DEBQ) for assessment of restrained, emotional, and external eating behavior. Int J Eat Disord. 1986;5:295315

24. Viana V, Sinde S. Estilo alimentar: Adaptação e validação do questionário holandês do comportamento alimentar. Psicologia: Teoria, Investigação e Prática. 2003;8:59-71.

25. Gormally J, Black S, Daston S, Rardin D. The assessment of binge eating severity among obese persons. Addict Behav. 1982;7:47-55.

26. Garner DM, Olmstead MP, Polivy J. Development and validation of a multidimensional eating disorder inventory for anorexia nervosa and bulimia. Int J Eat Disord. 1983:2:15-34.

27. Machado PP, Gonçalves S, Martins C, Soares IC. The Portuguese version of the eating disorders inventory: Evaluation of its psychometric properties. Eur Eat Disord Rev. 2001;9:43-52.

28. Weiss BD, Mays MZ, Martz W, Castro KM, DeWalt DA, Pignone MP, et al. Quick assessment of literacy in primary care: the newest vital sign. Ann Fam Med. 2005;3:514-22.

29. Santos O, Oliveira A, Carvalho C, et al. Self-administration of the Newest Vital Sign in Portuguese young adults: study of its internal reliability. $12^{\text {th }}$ International Congress of Behavioral Medicine. Budapest: Int J Behav Med; 2012.

30. Breslow NE, Day NE. Statistical methods in cancer research. The Analysis of Case-Control Studies. Lyon: IARC Sci Publ; 1986. p. 79-31.

31. Streiner DL. Starting at the beginning: an introduction to coefficien alpha and internal consistency. J Pers Assess. 2003;80:99-103.

32. Yoshikawa T, Orita K, Watanabe Y, Tanaka M. Validation of the Japanese version of the Power of Food Scale in a young adult population. Psychol Rep. 2012;111:253-65.

33. Koenders PG, van Strien T. Emotional eating, rather than lifestyle behavior, drives weight gain in a prospective study in 1562 employees. J Occup Environ Med. 2011;53:1287-93.

34. Sung J, Lee K, Song YM. Relationship of eating behavior to long-term weight change and body mass index: the Healthy Twin study. Eat Weight Disord. 2009;14:e98-105.

35. Pepino MY, Stein RI, Eagon JC, Klein S. Bariatric surgery-induced weight loss causes remission of food addiction in extreme obesity. Obesity. 2014;22:1792-8.

36. Ullrich J, Ernst B, Wilms B, Thurnheer M, Schultes B. Roux-en-Y gastric bypass surgery reduces hedonic hunger and improves dietary habits in severely obese subjects. Obes Surg. 2013;23:50-5. 
Gabriela RIBEIRO, Osvaldo SANTOS, Marta CAMACHO, Sandra TORRES, Filipa MUCHA-VIEIRA, Daniel SAMPAIO, Albino J. OLIVEIRA-MAIA

\section{Translation, Cultural Adaptation and Validation of the Power of Food Scale for Use by Adult Populations in Portugal}

Acta Med Port 2015:28:575-582

Publicado pela Acta Médica Portuguesa, a Revista Científica da Ordem dos Médicos

Av. Almirante Gago Coutinho, 151

1749-084 Lisboa, Portugal.

Tel: +351218428 215

E-mail: submissao@actamedicaportuguesa.com

www.actamedicaportuguesa.com

ISSN:0870-399X | e-ISSN: 1646-0758

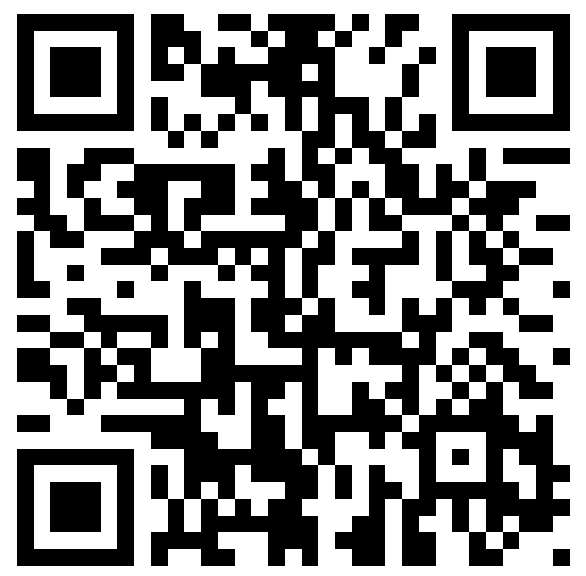

ACTA MÉDICA

PORTUGUESA 